\title{
Energy, Exergy and Thermoeconomics Analysis of Water Chiller Cooler for Gas Turbines Intake Air Cooling
}

\author{
Galal Mohammed Zaki ${ }^{1}$, Rahim Kadhim Jassim², Majed Moalla Alhazmy ${ }^{1}$ \\ ${ }^{1}$ Department of Thermal Engineering and Desalination Technology, King Abdulaziz University, Jeddah, Saudi Arabia; ${ }^{2}$ Department \\ of Mechanical Engineering Technology, Yanbu Industrial College, Yanbu Industrial City, Saudi Arabia. \\ Email: \{gzaki; mhazmy\}@kau.edu.sa,rkjassim@yic.edu.sa.
}

Received June 24, 2010; revised May 23, 2011; accepted May 30, 2011.

\begin{abstract}
Gas turbine (GT) power plants operating in arid climates suffer a decrease in output power during the hot summer months because of the high specific volume of air drawn by the compressor. Cooling the air intake to the compressor has been widely used to mitigate this shortcoming. Energy and exergy analysis of a GT Brayton cycle coupled to a refrigeration air cooling unit shows a promise for increasing the output power with a little decrease in thermal efficiency. A thermo-economics algorithm is developed to estimate the economic feasibility of the cooling system. The analysis is applied to an open cycle, HITACHI-FS7001B GT plant at the industrial city of Yanbu (Latitude $24^{\circ} 05^{\prime \prime} \mathrm{N}$ and longitude $38^{\circ}$ E) by the Red Sea in the Kingdom of Saudi Arabia. Result show that the enhancement in output power depends on the degree of chilling the air intake to the compressor (a $12-22 \mathrm{~K}$ decrease is achieved). For this case study, maximum power gain ratio (PGR) is $15.46 \%$ (average of $12.25 \%$ ), at an insignificant decrease in thermal efficiency. The second law analysis show that the exergetic power gain ratio drops to an average $8.5 \%$. The cost of adding the air cooling system is also investigated and a cost function is derived that incorporates time-dependent meteorological data, operation characteristics of the GT and the air intake cooling system and other relevant parameters such as interest rate, lifetime, and operation and maintenance costs. The profit of adding the air cooling system is calculated for different electricity tariff.
\end{abstract}

Keywords: Gas Turbine, Exergy Analysis, Power Boosting, Hot Climate, Air cooling, Water Chiller

\section{Introduction}

During hot summer months, the demand for electricity increases and utilities may experience difficulty meeting the peak loads, unless they have sufficient reserves. In all Gulf States, where the weather is fairly hot year around, air conditioning $(\mathrm{A} / \mathrm{C})$ is a driving factor for electricity demand and operation schedules. The utilities employ gas turbine (GT) power plants to meet the A/C peak load. Unfortunately, the power output and thermal efficiency of GT plants decrease in the summer because of the increase in the compressor power. The lighter hot air at the GT intake decreases the mass flow rate and in turn the net output power. For an ideal GT open cycle, the decrease in the net output power is $-0.4 \%$ for every $1 \mathrm{~K}$ increase in the ambient air temperature. To overcome this problem, air intake cooling methods, such as evaporative (direct method) and/or refrigeration (indirect method) has been widely considered [1].

In the direct method of evaporative cooling, the air intake cools off by contacts with a cooling fluid, such as atomized water sprays, fog or a combination of both, [2] . Evaporative cooling has been extensively studied and successfully implemented for cooling the air intake in GT power plants in dry hot regions [3-7]. This cooling method is not only simple and inexpensive, but the water spray also reduces the NOx content in the exhaust gases. Recently, Sanaye and Tahani [8] investigated the effect of using a fog cooling system, with 1 and $2 \%$ over-spray, on the performance of a combined GT; they reported an improvement in the overall cycle heat rate for several GT models. Although evaporative cooling systems have low capital and operation cost, reliable and require moderate maintenance, they have low operation efficiency, consume large quantities of water and the impact of the non evaporated water droplets in the air stream could damage 
the compressor blades [9]. The water droplets carryover and the resulting damage to the compressor blades, limit the use of evaporative cooling to areas of dry atmosphere. In these areas, the air could not be cooled below the wet bulb temperature (WBT). Chaker, et al. [10-12], Homjimeher, et al. [13] and Gajjar, et al. [14] have presented results of extensive theoretical and experimental studies covering aspects of fogging flow thermodynamics, droplets evaporation, atomizing nozzles design and selection of spray systems as well as experimental data on testing systems for gas turbines up to $655 \mathrm{MW}$ in a combined cycle plant.

In the indirect mechanical refrigeration cooling approach the constraint of humidity is eliminated and the air temperature can be reduced well below the ambient WBT. The mechanical refrigeration cooling has gained popularity over the evaporative method and in KSA, for example, 32 GT units have been outfitted with mechanical air chilling systems. There are two approaches for mechanical air cooling; either using vapor compression (Alhazmy [7] and Elliott [15]) or absorption refrigerator machines (Yang, et al. [16], Ondryas, et al. [17], Punwani [18] and Kakarus, et al. [19]). In general, application of the mechanical air-cooling increases the net power but in the same time reduces the thermal efficiency. For example, Alhazmy, et al. [6] showed that for a GT of pressure ratio 8 cooling the intake air from $50^{\circ} \mathrm{C}$ to $40^{\circ} \mathrm{C}$ increases the power by $3.85 \%$ and reduces the thermal efficiency by $1.037 \%$. Stewart and Patrick [20] raised another disadvantage (for extensive air chilling) concerning ice formation either as ice crystals in the chilled air or as solidified layer on air compressors' entrance surfaces.

Recently, alternative cooling approaches have been investigated. Farzaneh-Gord and Deymi-Dashtebayaz [21] proposed improving refinery gas turbines performance using the cooling capacity of refinerys' natural-gas pressure drop stations. Zaki, et al. [22] suggested a reverse Brayton refrigeration cycle for cooling the air intake; they reported an increase in the output power up to $20 \%$, but a $6 \%$ decrease in thermal efficiency. This approach was further extended by Jassim, et al. [23] to include the exergy analysis and show that the second law analysis improvement has dropped to $14.66 \%$ due to the components irreversibilities. Khan, et al. [24] analyzed a system in which the turbine exhaust gases are cooled and fed back to the compressor inlet with water harvested out of the combustion products. Erickson [25,26] suggested using a combination of a waste heat driven absorption air cooling with water injection into the combustion air; the concept is named the "power fogger cycle".

Thermal analyses of GT cooling are abundant in the literature, but few investigations considered the economics of the cooling process. A sound economic evaluation of implementing an air intake GT cooling system is quite involving. Such an evaluation should account for the variations in the ambient conditions (temperature and relative humidity) and the fluctuations in the fuel and electricity prices and interest rates. Therefore, the selection of a cooling technology (evaporative or refrigeration) and the sizing out of the equipment should not be based solely on the results of a thermal analysis but should include estimates of the cash flow. Gareta, et al. [27] has developed a methodology for combined cycle GT that calculated the additional power gain for 12 months and the economic feasibility of the cooling method. From an economical point of view, they provided straight forward information that supported equipment sizing and selection. Chaker, et al. [12] have studied the economical potential of using evaporative cooling for GTs in USA, while Hasnain [28] examined the use of ice storage methods for GTs' air cooling in KSA. Yang, et al. [16] presented an analytical method for evaluating a cooling technology of a combined cycle GT that included parameters such as the interest rate, payback period and the efficiency ratio for off-design conditions of both the GT and cooling system. Investigations of evaporative cooling and steam absorption machines showed that inlet fogging is superior in efficiency up to intake temperatures of 15 $20^{\circ} \mathrm{C}$, though it results in a smaller profit than inlet air chilling [16].

In the present study, the performance of a cooling system that consists of a chilled water external loop coupled to the GT entrance is investigated. The analysis accounts for the changes in the thermodynamics parameters (applying the first and second law analysis) as well as the economic variables such as profitability, cash flow and interest rate. An objective of the present study is to assess the importance of using a coupled thermo-economics analysis in the selections of the cooling system and operation parameters. The developed algorithm is applied to an open cycle, HITACH MS-7001B plant in the hot weather of KSA (Latitude $24^{\circ} 05^{\prime \prime} \mathrm{N}$ and longitude $38^{\circ} \mathrm{E}$ ) by the result of this case study are presented and discussed.

\section{GT-Air Cooling Chiller Energy Analysis}

Figure 1(a) shows a schematic of a simple open GT "Brayton cycle" coupled to a refrigeration system. The power cycle consists of a compressor, combustion chamber and a turbine. It is presented by states 1-2-3-4 on the T-S diagram, Figure 1(b). The cooling system consists of a refrigerant compressor, air cooled condenser, throttle valve and water cooled evaporator. The chilled water from the evaporator passes through a cooling coil mounted at the air compressor entrance, Figure 1(a). The refrigerant cycle is presented on the T-S diagram, Figure $\mathbf{1}(\mathbf{c})$, by states $a, b, c$ and $d$. A fraction of the power pro- 


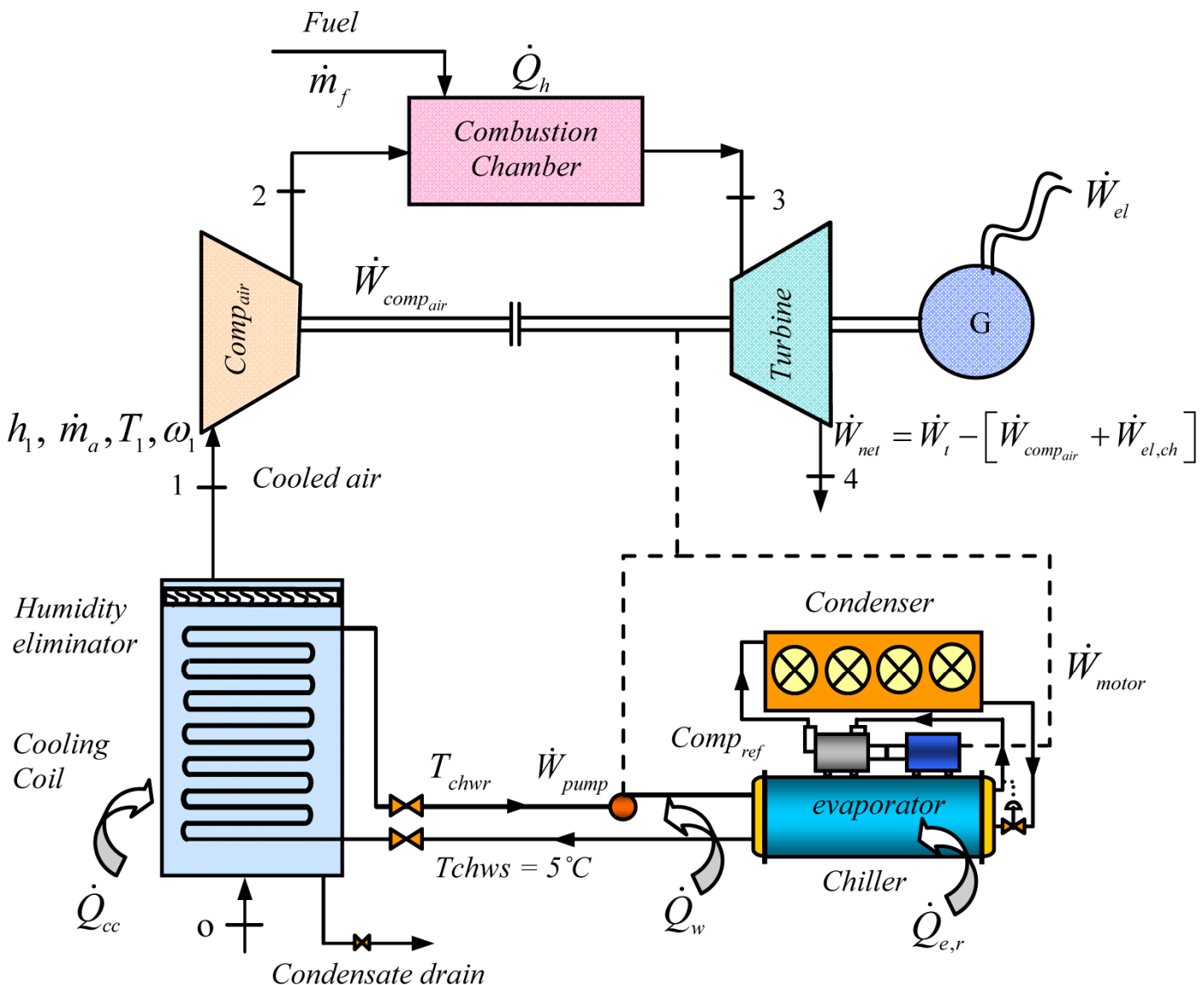

(a)

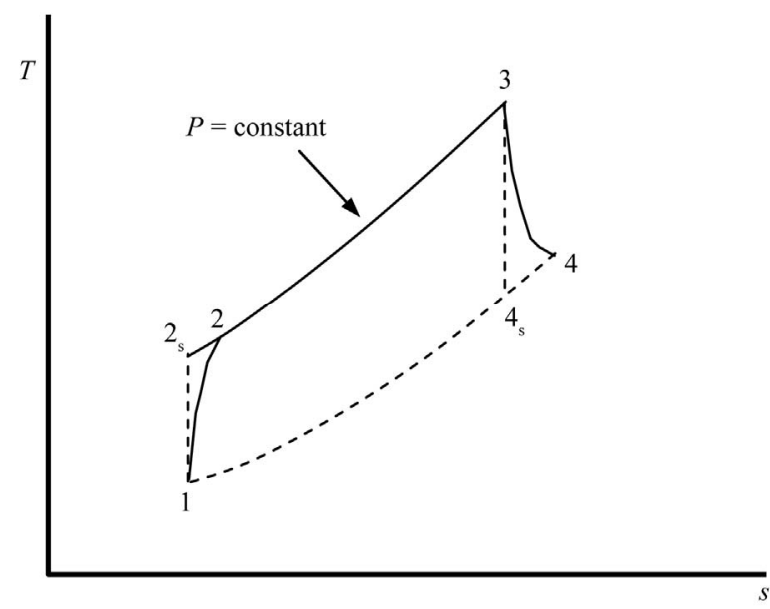

(b)

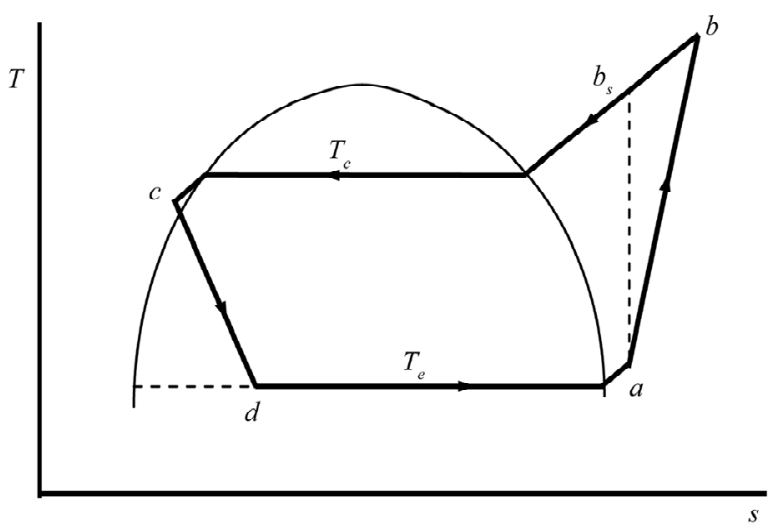

(c)

Figure 1. (a) Simple open type gas turbine with a chilled air-cooling unit; (b) $T$-s diagram of an open type gas turbine cycle; (c) $T$-s diagram for a refrigeration machine.

duced by the turbine is used to power the refrigerant compressor and the chilled water pumps, as indicated by the dotted lines in Figure 1(a). To investigate the performance of the coupled GT-cooling system the different involved cycles are analyzed in the following employing the first and second laws of thermodynamics.

\subsection{Gas Turbine Cycle}

As seen in Figures 1(a) and (b), processes 1-2 and 3-4 are isentropic. Assuming the air as an ideal gas, the tem- 
peratures and pressures are related to the pressure ratio, $P R$, by:

$$
\frac{T_{2 s}}{T_{1}}=\frac{T_{3}}{T_{4 s}}=\left[\frac{P_{2}}{P_{1}}\right]^{\frac{k-1}{k}}=P R^{\frac{k-1}{k}}
$$

The net power output of a GT with mechanical cooling system as seen in Figures 1(a) is

$$
\dot{W}_{n e t}=\dot{W}_{t}-\left(\dot{W}_{\text {comp }}+\dot{W}_{e l, c h}\right)
$$

The first term of the RHS is the power produced by the turbine due to expansion of hot gases;

$$
\dot{W}_{t}=\dot{m}_{t} c_{p g} \eta_{t}\left(T_{3}-T_{4 s}\right)
$$

In Equation (3), $\dot{m}_{t}$ is the total gases mass flow rate from the combustion chamber; expressed in terms of the fuel air ratio $f=\dot{m}_{f} / \dot{m}_{a}$, and the air humidity ratio at the compressor intake $\omega_{1},\left(\mathrm{~kg}_{w} / \mathrm{kg}_{\text {dry air }}\right)$ (Figures 1(a)) as;

$$
\dot{m}_{t}=\dot{m}_{a}+\dot{m}_{v}+\dot{m}_{f}=\dot{m}_{a}\left(1+\omega_{1}+f\right)
$$

The compression power for humid air between states 1 and 2 is estimated from:

$$
\dot{W}_{\text {comp }}=\dot{m}_{a} c_{p a}\left(T_{2}-T_{1}\right)+\dot{m}_{v}\left(h_{v 2}-h_{v 1}\right)
$$

where $h_{v 2}$ and $h_{v 1}$ are the enthalpies of saturated water vapor at the compressor exit and inlet states respectively, $\dot{m}_{v}$ is the mass of water vapor $=\dot{m}_{a} \omega_{1}$.

The last term in Equation (2) $\left(\dot{W}_{e l, c h}\right)$ is the power consumed by the cooling unit for driving the refrigeration machine electric motor, pumps and auxiliaries.

The thermal efficiency of a GT coupled to an air cooling system is then;

$$
\eta_{c y}=\frac{\dot{W}_{t}-\left(\dot{W}_{c o m p}+\dot{W}_{e l, c h}\right)}{\dot{Q}_{h}}
$$

Substituting for $T_{4 s}$ and $\dot{m}_{t}$ from Equations (1) and (4) into Equations (3) yields:

$$
\dot{W}_{t}=\dot{m}_{a}\left(1+\omega_{1}+f\right) c_{p g} \eta_{t} T_{3}\left(1-\frac{1}{P R^{\frac{k-1}{k}}}\right)
$$

The turbine isentropic efficiency, $\eta_{t}$, can be estimated using the practical relation recommended by Alhazmy and Najjar [6]:

$$
\eta_{t}=1-\left(0.03+\frac{P R-1}{180}\right)
$$

Relating the compressor isentropic efficiency to the changes in temperature of the dry air and assuming that the compression of water vapor changes the enthalpy; the actual compressor power becomes;

$$
\dot{W}_{\text {comp } a i r}=\dot{m}_{a}\left[c_{p a} \frac{\mathrm{T}_{1}}{\eta_{\mathrm{c}}}\left(P R^{\frac{k-1}{k}}-1\right)+\omega_{1}\left(h_{v 2}-h_{v 1}\right)\right]
$$

The compression efficiency, $\eta_{c}$, can be evaluated using the following empirical relation, Alhazmy and Najjar [6];

$$
\eta_{c}=1-\left(0.04+\frac{P R-1}{150}\right)
$$

The heat balance in the combustion chamber (Figure 1(a)) gives the heat rate supplied to the gas power cycle as:

$$
\begin{aligned}
& \dot{Q}_{h}=\dot{m}_{f} N C V \eta_{c o m b} \\
& =\left(\dot{m}_{a}+\dot{m}_{f}\right) c_{p g} T_{3}-\dot{m}_{a} c_{p a} T_{2}+\dot{m}_{v}\left(h_{v 3}-h_{v 2}\right)
\end{aligned}
$$

Introducing the fuel air ratio $f=\dot{m}_{f} / \dot{m}_{a}$ and substituting for $T_{2}$ in terms of $T_{1}$ into Equation (12) yields:

$$
\begin{aligned}
& \dot{Q}_{h}=\dot{m}_{a} T_{1} \\
& \cdot\left[(1+f) c_{p g} \frac{T_{3}}{T_{1}}-c_{p a}\left(\frac{P R^{\frac{k-1}{k}}-1}{\eta_{c}}+1\right)+\frac{\omega_{1}}{T_{1}}\left(h_{v 3}-h_{v 2}\right)\right]
\end{aligned}
$$

A simple expression for $f$ is selected here, Alhazmy, et al. [7] as:

$$
f=\frac{c_{p g}\left(T_{3}-298\right)-c_{p a}\left(T_{2}-298\right)+\omega_{1}\left(h_{v 3}-h_{v 2}\right)}{N C V \eta_{c o m b}-c_{p g}\left(T_{3}-298\right)}
$$

In Equation (14), $h_{v 2}$ and $h_{v 3}$ are the enthalpies of water vapor at the combustion chamber inlet and exit states respectively and can be calculated from Equation (15), Dossat [29].

$$
h_{v, j}=2501.3+1.8723 T_{j} \quad j \text { refers to states } 2 \text { or } 3
$$

The four terms of the gas turbine net power and efficiency in Equation (6) $\left(\dot{W}_{t}, \dot{W}_{\text {comp }}, \dot{W}_{\text {el,ch }}\right.$ and $\left.\dot{Q}_{h}\right)$ depend on the air temperature and relative humidity at the compressor inlet whose values are affected by the type and performance of the cooling system. The chillers' electric power, $\dot{W}_{e l, c h}$, is calculated in the following account.

\subsection{Refrigeration Cooling System Analysis}

The chilled water from the refrigeration machine is the heat transport fluid to cool the intake air, Figure 1(a). The chiller's total electrical power can be expressed as the sum of the electric motor power $\left(\dot{W}_{\text {motor }}\right)$, the pumps $\left(\dot{W}_{P}\right)$ and auxiliary power for fans and control units, $\left(\dot{W}_{A}\right)$ as:

$$
\dot{W}_{e l, c h}=\dot{W}_{\text {motor }}+\dot{W}_{P}+\dot{W}_{A}
$$


The auxiliary power is estimated as $10 \%$ of the compressor power, therefore, $\dot{W}_{A}=0.1 \dot{W}_{\text {motor }}$. The second term in Equation (16) is the pumping power that is related to the chilled water flow rate and the pressure drop across the cooling coil, so that:

$$
\dot{W}_{P}=\dot{m}_{c w} v_{f}(\Delta P) / \eta_{\text {pump }}
$$

The minimum energy utilized by the refrigerant compressor is that for the isentropic compression process ( $a-$ $b_{s}$ ), Figure 1(c). The actual power includes losses due to mechanical transmission, inefficiency in the drive motor converting electrical to mechanical energy and the volumetric efficiency, Dossat [29]. The compressor electric motor work is related to the refrigerant enthalpy change as

$$
\dot{W}_{\text {motor }}=\frac{\dot{m}_{r}\left(h_{b}-h_{a}\right)_{r}}{\eta_{e u}}
$$

The subscript $r$ indicates refrigerant and $\eta_{e u}$ known as the energy use factor; $\eta_{e u}=\eta_{m} \times \eta_{e l} \times \eta_{v o}$. The quantities on the right hand side are the compressor mechanical, electrical and volumetric efficiencies respectively. $\eta_{e u}$ is usually determined by manufacturers and depends on the type of the compressor, the pressure ratio $\left(P_{b} / P_{a}\right)$ and the motor power. For the present analysis $\eta_{e u}$ is assumed $85 \%$.

Cleland, et al. [30] developed a semi-empirical form of Equation (18) to calculate the compressor's motor power usage in terms of the temperatures of the evaporator and condenser in the refrigeration cycle, $T_{e}$ and $T_{c}$ respectively as;

$$
\dot{W}_{\text {motor }}=\frac{\dot{m}_{r}\left(h_{a}-h_{d}\right)_{r}}{\frac{T_{e}}{\left(T_{c}-T_{e}\right)}(1-\alpha x)^{n} \eta_{e u}}
$$

In this equation, $\alpha$ is an empirical constant that depends on the type of refrigerant and $x$ is the quality at state $d$, Figure 1(c). The empirical constant is 0.77 for R-22 and 0.69 for R-134a Cleland, et al. [30]. The constant $n$ depends on the number of the compression stages; for a simple refrigeration cycle with a single stage compressor $n=1$. The nominator of Equation (19) is the evaporator capacity, $\dot{Q}_{e, r}$ and the first term of the denominator is the coefficient of performance of an ideal refrigeration cycle. Equations (2), (5) and (19) could be solved for the power usages by the different components of the coupled GT-refrigeration system to estimate the increase in the power output as function of the air intake conditions. Follows is a thermodynamics second law analysis to estimate the effect of irreversibilities on the power gain and efficiency.

\section{Exergy Analysis}

In general, the expression for the exergy destruction,
(Kotas [31]), is.

$$
\dot{\mathrm{I}}=\mathrm{T}_{\mathrm{o}}\left[\left(\dot{\mathrm{S}}_{\text {out }}-\dot{\mathrm{S}}_{\text {in }}\right)-\sum_{\mathrm{i}=1}^{\mathrm{n}} \frac{\dot{\mathrm{Q}}_{\mathrm{i}}}{\mathrm{T}_{\mathrm{i}}}\right] \geq 0
$$

and the exergy balance for any component of the coupled GT and refrigeration cooling cycle (Figure 1) is expressed as;

$$
\dot{E}_{\text {in }}+\dot{E}^{Q}=\dot{E}_{\text {out }}+\dot{W}+\dot{I}
$$

Various amounts of the exergy destruction terms due to irreversibility for each component in the gas turbine and the proposed air cooling system are given in final expressions, Table 1. Details of derivations can be found in Jassim, et al. [32,23] and Khir, et al. [33].

\section{Economics Analysis}

The increase in the power output due to intake air cooling will add to the revenue of the GT plant but will partially offset by the increase of the annual payments associated with the installation, personnel and utility expenditures for the operation of that system. For a cooling unit that includes a water chiller, the increase in expenses include the capital installments for the chiller, $\left(C_{c h}^{c}\right)$, and cooling coil, $\left(C_{c c}^{c}\right)$. The annual operation expenses is a function of the operation period, $t_{o p}$, and the electricity rate. If the chiller consumes electrical power $\dot{W}_{e l, c h}$ and the electricity rate is $C_{e l}(\$ / \mathrm{kWh})$ then the total annual expenses can be expressed as:

$$
C_{\text {total }}=a^{c}\left[C_{c h}^{c}+C_{c c}^{c}\right]+\int_{0}^{t_{\mathrm{op}}} C_{e l} \dot{W}_{e l, c h} \mathrm{~d} t \quad(\$ / \mathrm{y})
$$

In Equation (37), the capital recovery factor $a^{c}=\frac{i(1+i)^{n}}{(1+i)^{n}-1}$, which when multiplied by the total investment gives the annual payment necessary to payback the investment after a specified period $(n)$.

The chiller's purchase cost may be estimated from venders data or mechanical equipment cost index; this cost is related to the chiller's capacity, $\dot{Q}_{e, r}(\mathrm{~kW})$. For a particular chiller size and method of construction and installation; the capital cost is usually given by manufacturers in the following form;

$$
C_{c h}^{c}=\alpha_{c h} \dot{Q}_{e, r}
$$

For simplicity, the maintenance expenses are assumed as a fraction, $\alpha_{m}$, of the chiller capital cost, therefore, the total chiller cost is expressed as;

$$
C_{c h}^{c}=\alpha_{c h}\left(1+\alpha_{m}\right) \dot{Q}_{e, r}
$$

Similarly, the capital cost of a particular cooling coil is given by manufacturers in terms of the cooling capacity 
Table 1. Exergy destruction terms for the individual components of the GT and coupled cooling chilled water unit, see Figures 1(a)-(c).

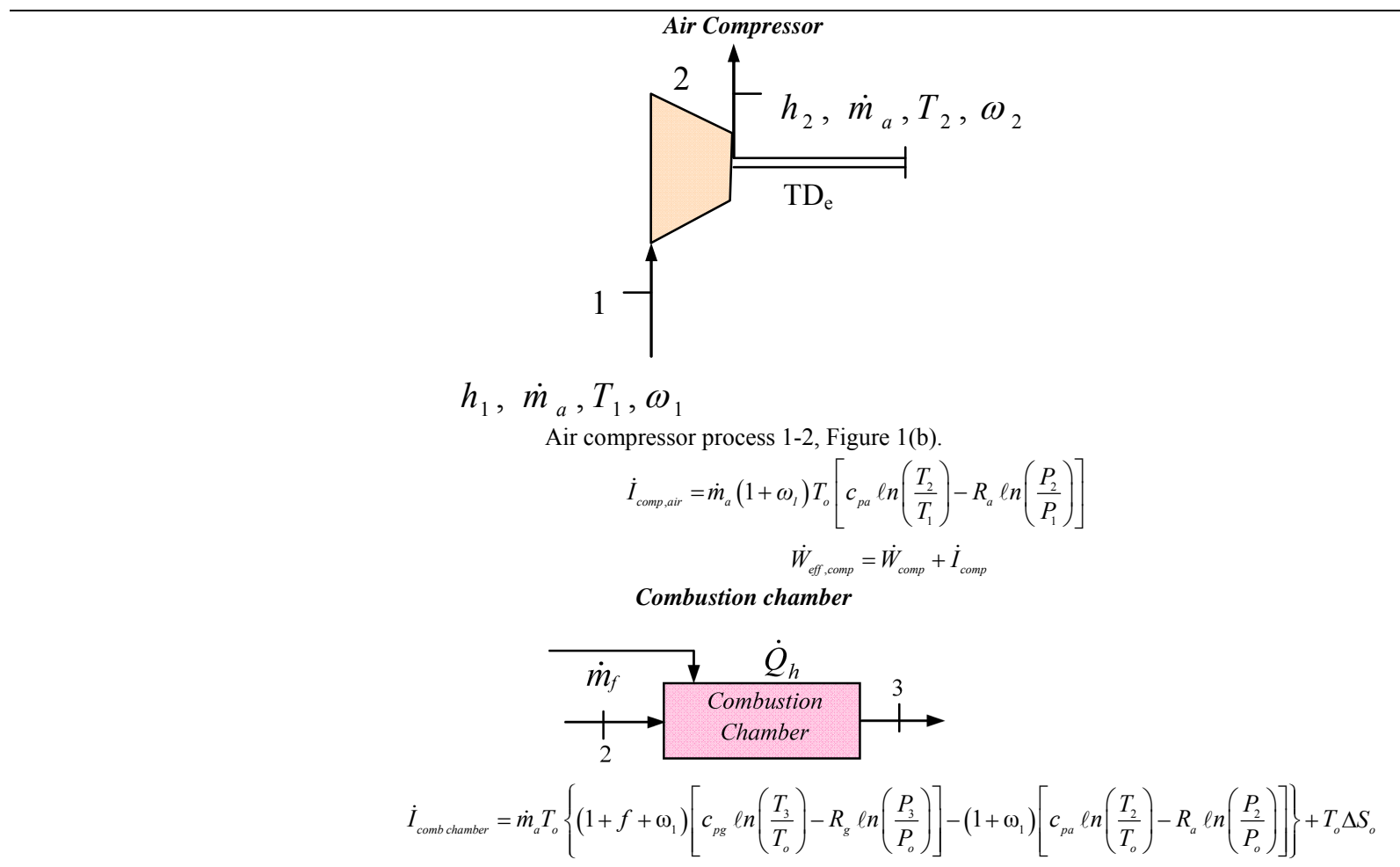

$T_{o} \Delta S_{o}=$ rate of exergy loss in combustion or reaction $=\dot{m}_{a} \times f \times N C V(\varphi-1)$

Typical values of $\varphi$. for some industrial fuels are given by Jassim, et al. [32], the effective heat to the combustion chamber

$$
\dot{Q}_{\text {eff }, \text { comb }}=\dot{Q}_{\text {comb }}+\dot{I}_{\text {comb }}
$$

Gas turbine

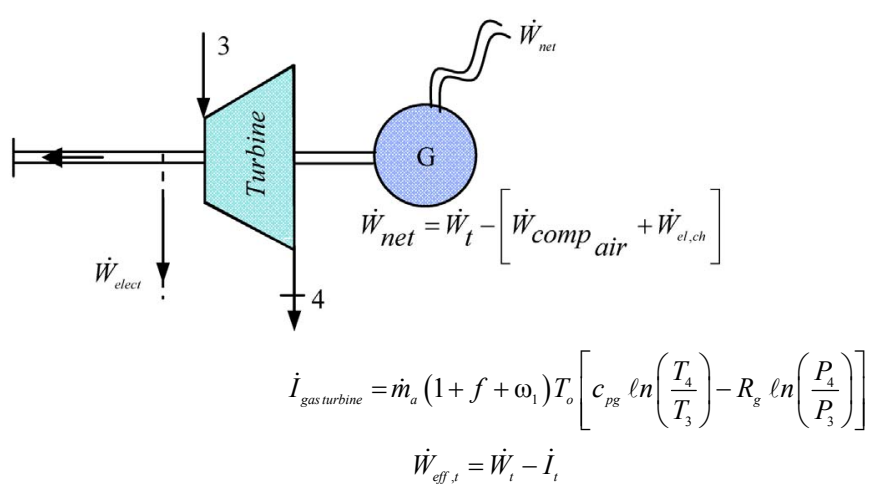

Chiller compressor

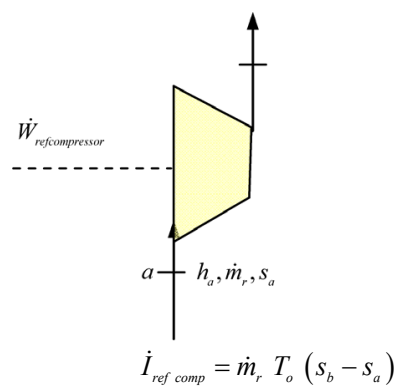




\section{Chiller Condenser}

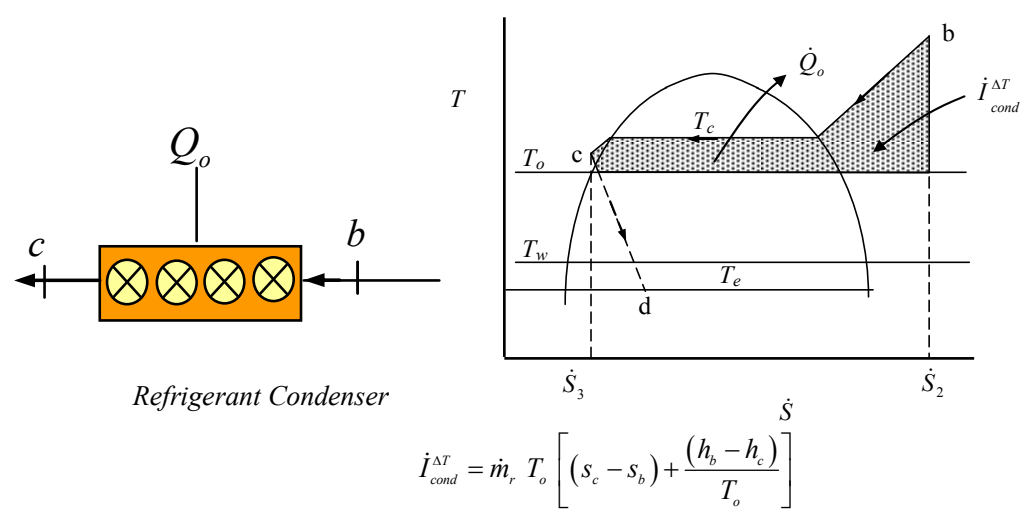

The condenser flow is divided into three regions: superheated vapor region, two phase (saturation) region, and subcooled liquid region for which the exergy destruction due to flow pressure losses in each region are $\dot{I}_{\text {cond, sup }}^{\Delta P}, \dot{I}_{\text {cond, sat }}^{\Delta P}$ and $\dot{I}_{\text {cond sub }}^{\Delta P}$. (Jassim, et al. [23])

$$
\begin{gathered}
\dot{I}_{\text {cond }}^{\Delta P}=\dot{I}_{\text {cond sup }}^{\Delta P}+\dot{I}_{\text {cond sat }}^{\Delta P}+\dot{I}_{\text {cond }, \text { sub }}^{\Delta P} \\
\dot{I}_{\text {cond }}=\dot{I}_{\text {cond }}^{\Delta T}+\dot{I}_{\text {cond }}^{\Delta P}
\end{gathered}
$$

Chiller cooling coil

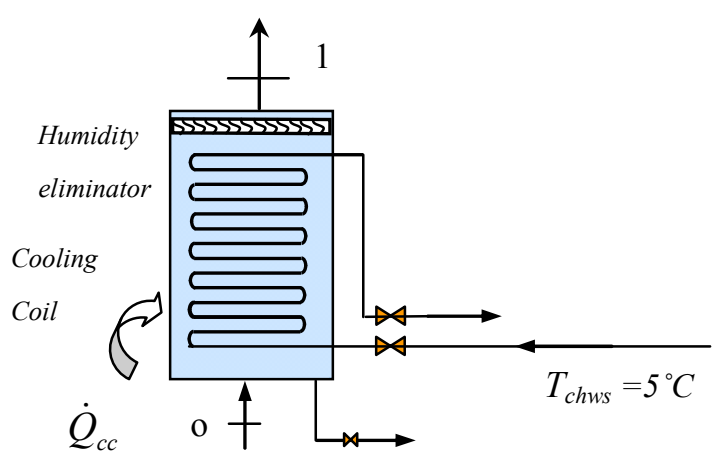

Condensate drain

$$
\dot{I}_{\text {cooling coil }}=\dot{m}_{a}\left(1+\omega_{1}\right) T_{o}\left(\mathrm{~s}_{\mathrm{o}}-\mathrm{s}_{1}\right)+\dot{Q}_{\text {out }}
$$

Expansion valve

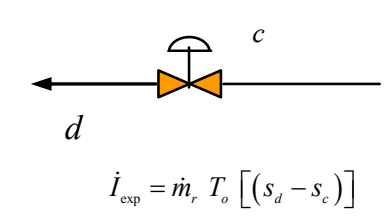

Refrigerant evaporator
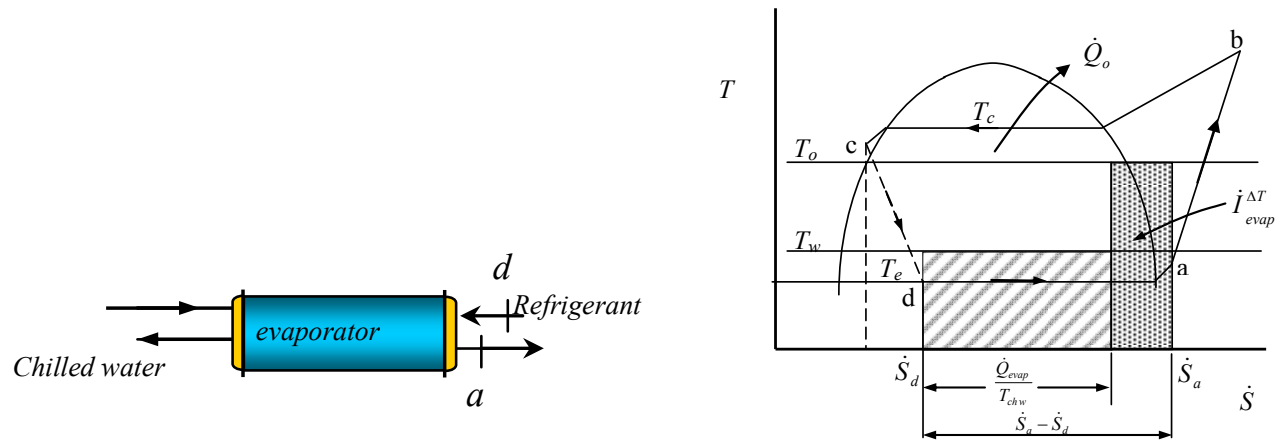


$$
\dot{I}_{\text {evap }}^{\Delta T}=\dot{m}_{r} T_{o}\left[\left(s_{a}-s_{d}\right)-\frac{\left(h_{a}-h_{d}\right)}{T_{s w}}\right]
$$

The refrigerant flow in the evaporator is divided into two regimes saturation (two phase) and superheated regions. The two phase (saturation) region, and superheated vapor region for which the exergy destruction due to flow pressure losses in each region are $\dot{I}_{\text {evap sat }}^{\Delta P}$, $\dot{I}_{\text {evap sup }}^{\Delta P}$ see Khir, et al. [33]. The exergy destruction rate is the sum of the thermal and pressure loss terms for both regimes (Equations (35) and (36)) as,

$$
\begin{gathered}
\dot{I}_{\text {evap }}=\dot{I}_{\text {evap }}^{\Delta T}+\dot{I}_{\text {evap }}^{\Delta P} \\
\dot{I}_{\text {evap }}^{\Delta P}=\dot{I}_{\text {evap }, \text { sat }}^{\Delta P}+\dot{I}_{\text {evap }, \text { sup }}^{\Delta P}
\end{gathered}
$$

that is directly proportional to the total heat transfer surface area $\left(A_{c c}, \mathrm{~m}^{2}\right)$ Kotas [31]) as,

$$
C_{c c}^{c}=\beta_{c c}\left(A_{c c}\right)^{m}
$$

In Equation (40), $\beta_{c c}$ and $m$ depend on the type of the cooling coil and material. For the present study and local Saudi market, $\beta_{c c}=30000$ and $m=0.582$ are recommended (York Co consultation [34]). Substituting Equations (39) and (40) into Equation (37), assuming for simplicity that the chiller power is an average constant value and constant electricity rate over the operation period, the annual total expenses for the cooling system become;

$$
C_{\text {total }}=a^{c}\left[\alpha_{c h}\left(1+\alpha_{m}\right) \dot{Q}_{e, r}+\beta_{c c}\left(A_{c c}\right)^{m}\right]+t_{o p} C_{e l} \dot{W}_{e l, c h}
$$

In Equation (41) the heat transfer area $A_{c c}$ is the parameter used to evaluate the cost of the cooling coil. Energy balance on both the cooling coil and the refrigerant evaporator, taking into account the effectiveness factors for the evaporator, $\varepsilon_{\text {eff,er }}$, and the cooling coil, $\varepsilon_{e f f, c c}$, gives

$$
A_{c c}=\frac{\dot{Q}_{c c}}{U \Delta T_{m} F \varepsilon_{e f f, c c}}=\frac{\dot{Q}_{e, r} \varepsilon_{e f f, e r}}{U \Delta T_{m} F}
$$

where, $U$ is the overall heat transfer coefficient for chilled water-air tube bank heat exchanger. Gareta, et al. [27] suggested a moderate value of $64 \mathrm{~W} / \mathrm{m}^{2} \mathrm{~K}$ and 0.98 for the correction factor $F$.

Figure 2, illustrates the temperature variations in the combined refrigerant, water chiller and air cooling system. the mean temperature difference for the cooling coil (air and chilled water fluids) is;

$$
\Delta T_{m}=\frac{\left(T_{o}-T_{c h w r}\right)-\left(T_{1}-T_{c h w s}\right)}{\ln \left(\left(T_{o}-T_{c h w r}\right) /\left(T_{1}-T_{c h w s}\right)\right)}
$$

Equations (40) and (42) give the cooling coil cost as,

$$
C_{c c}^{c}=\beta_{c c}\left(\frac{\dot{Q}_{c c}}{U \Delta T_{m} F}\right)^{m}
$$

where, $\dot{Q}_{c c}$ is the thermal capacity of the cooling coil. The atmospheric air enters at $T_{o}$ and $\omega_{o}$ and leaves the cooling coil to enter the air compressor intake at $T_{1}$ and $\omega_{1}$, Figure 1(a). Both $T_{1}$ and $\omega_{1}$ depend on the chilled water supply temperature $\left(T_{c h w s}\right)$ and mass flow rate, $\dot{m}_{c w}$. When the outer surface temperature of the cooling coil falls below the dew point (corresponding to the partial pressure of the water vapor) the water vapor condensates and leaves the air stream. This process may be treated as a cooling-dehumidification process as illustrated in Figure 3. Steady state heat balance of the cooling coil gives;

$$
\dot{Q}_{c c}=\dot{m}_{a}\left(h_{o}-h_{1}\right)-\dot{m}_{w} h_{w}=\dot{m}_{c w} c_{w} \varepsilon_{e f f, c c}\left(T_{c h w r}-T_{c h w s}\right)
$$

where, $\dot{m}_{c w}$ is the chilled water mass flow rate and $\dot{m}_{w}$ is the rate of water extraction from the air, $\dot{m}_{w}=\dot{m}_{a}\left(\omega_{o}-\omega_{1}\right)$. The second term in Equation (45) is usually a small term when compared to the first and can be neglected, McQuiston, et al. [35].

In Equation (45) the enthalpy and temperature of the air leaving the cooling coil $\left(h_{1}\right.$ and $\left.T_{1}\right)$ may be calculated from;

$$
\begin{gathered}
h_{1}=h_{o}-C F\left(h_{o}-h_{s}\right) \\
T_{1}=T_{o}-C F\left(T_{o}-T_{s}\right)
\end{gathered}
$$

The contact factor $C F$ is defined as the ratio between the actual air temperature drop to the maximum, at which the air theatrically leaves at the coil surface temperature $T_{s}=T_{\text {chws }}$ and $100 \%$ relative humidity. Substituting for $h_{l}$ from Equation (46) into Equation (45) and use Equation (42) gives;

$$
\dot{Q}_{e, r}=\frac{\dot{m}_{a}\left[C F\left(h_{o}-h_{c h w s}\right)-\left(\omega_{o}-\omega_{1}\right) h_{w}\right]}{\varepsilon_{e f f, e r} \varepsilon_{e f f, c c}}
$$

Equations (41) through (48) give the chiller and cooling coil annual expenses in terms of the air mass flow rate and properties. The total annual cost function is derived from Equation (41) as follows.

\subsection{Annual Cost Function}

Combining Equations (41) and (42), substituting for the cooling coil surface area, pump and auxiliary power gives the total annual cost in terms of the evaporator capacity $\dot{Q}_{e r}$, as, 


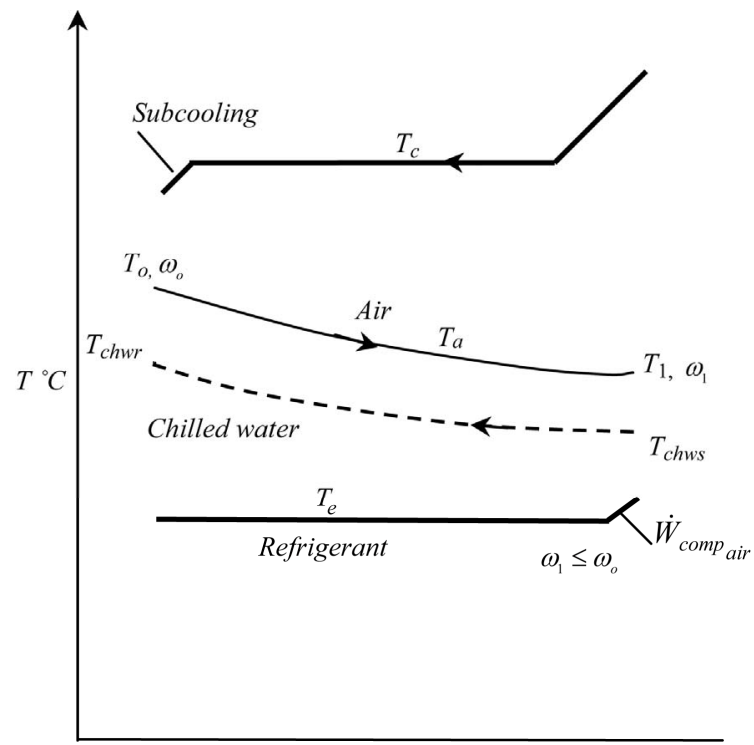

Figure 2. Temperature levels for the three working fluids, not to scale.

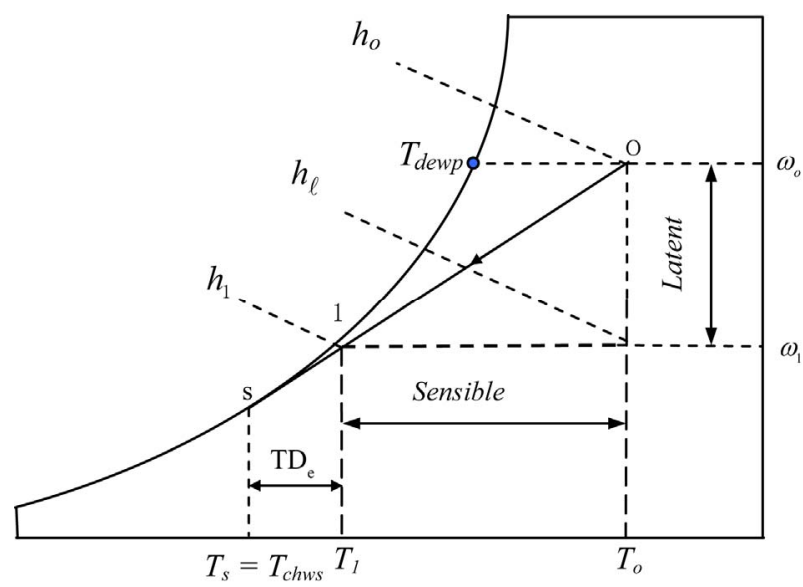

Figure 3. Moist air cooling process before GT compressor intake.

$$
\begin{aligned}
& C_{\text {total }}=\left\{a^{c}\left[\alpha_{c h}\left(1+\alpha_{m}\right) \dot{Q}_{e r}+\beta_{c c}\left(\frac{\dot{Q}_{e r} \varepsilon_{e f f, e r} \varepsilon_{e f f, c c}}{U \Delta T_{m} F}\right)^{m}\right]\right. \\
& \left.+t_{o p} \dot{Q}_{e r} C_{e l}\left[\left(\frac{1.1\left(T_{c}-T_{e}\right)}{T_{e}(1-\alpha x)^{n} \eta_{e u}}\right)+\left(\frac{\varepsilon_{e f f, e r} v_{f}(\Delta P)}{c_{p, w} \Delta T_{c h, w} \eta_{p u m p}}\right)\right]\right\}
\end{aligned}
$$

The first term in Equation (49) is the annual fixed charges of the refrigeration machine and the surface air cooling coil, while the second term is the operation expenses that depend mainly on the electricity rate. If the water pump's power is considered small compared to the compressor power, the second term of the operation charges can be dropped. If the evaporator capacity $\dot{Q}_{e r}$ is replaced by the expression in Equation (48), the cost function, in terms of the primary parameters, becomes;

$$
\begin{aligned}
C_{\text {total }}= & {\left[\frac{\dot{m}_{a}\left[C F\left(h_{o}-h_{c h w s}\right)-\left(\omega_{o}-\omega_{1}\right) h_{w}\right]}{\varepsilon_{e f f, e r} \varepsilon_{e f f, c c}}\right] } \\
\cdot\left\{a ^ { c } \left[\alpha_{c h}\left(1+\alpha_{m}\right)+\beta_{c c}\left(\frac{\varepsilon_{e f f, e r} \varepsilon_{e f f, c c}}{U \Delta T_{m} F}\right)^{m}\right.\right. & \\
& \left.\times\left(\frac{\dot{m}_{a}\left[C F\left(h_{o}-h_{c h w s}\right)-\left(\omega_{o}-\omega_{1}\right) h_{w}\right]}{\varepsilon_{e f f, e r} \varepsilon_{e f f, c c}}\right)^{m-1}\right] \\
+ & \left.t_{o p} C_{e l}\left[\left(\frac{1.1\left(T_{c}-T_{e}\right)}{\left(T_{e}\right)(1-\alpha x)^{n} \eta_{e u}}\right)+\left(\frac{\varepsilon_{e f f, e r} v_{f}(\Delta P)}{c_{p, w} \Delta T_{c h, w} \eta_{p}}\right)\right]\right\}
\end{aligned}
$$

\section{Evaluation Criteria of Gt-Cooling System}

In order to evaluate the feasibility of a cooling system coupled to a GT plant, the performance of the plant is examined with and without the cooling system. In the present study it is recommended to consider the results of the three procedures (energy, exergy and economics analysis).

\subsection{First Law Efficiency}

In general, the net power output of a complete system is given in Equation (2) in terms of $\dot{W}_{t}, \dot{W}_{\text {comp }}$ and $\dot{W}_{e l, c h}$. The three terms are functions of the air properties at the compressor intake $\left(T_{1}\right.$ and $\left.\omega_{1}\right)$, which in turn depend on the performance of the cooling system. The present analysis considers the "power gain ratio" $(P G R)$, a broad term suggested by AlHazmy, et al. [7] that takes into account the operation parameters of the GT and the associated cooling system:

$$
P G R=\frac{\dot{W}_{\text {net, with cooling }}-\dot{W}_{\text {net, without cooling }}}{\dot{W}_{\text {net, without cooling }}} \times 100 \%
$$

For a stand-alone GT, $P G R=0$. Thus, the $P G R$ gives the percentage enhancement in power generation by the coupled system. The thermal efficiency of the system is an important parameter to describe the input-output relationship. The thermal efficiency change factor (TEC) proposed in AlHazmy, et al. [7] is defined as

$$
T E C=\frac{\eta_{c y, \text { with cooling }}-\eta_{c y, \text { without cooling }}}{\eta_{c y, \text { without cooling }}} \times 100 \%
$$

\subsection{Exrgetic Efficiency}

Exergetic efficiency is a performance criterion for which the output is expressible in terms of exergy. Defining the exergetic efficiency $\eta_{e x}$, as a ratio of total rate of exergy output $\left(\dot{E}_{\text {out }}\right)$ to total rate of exergy input $\left(\dot{E}_{\text {in }}\right)$ as; 


$$
\eta_{\text {ex }}=\frac{\dot{E}_{\text {out }}}{\dot{E}_{\text {in }}}
$$

The exergy balance for the gas turbine and the water chiller system, using the effective work and heat terms in Table 1, can be expressed in the following forms,

$$
\dot{E}_{\text {out }}=\dot{W}_{\text {eff }, t}-\dot{W}_{\text {eff,comp }}-\dot{W}_{\text {eff, Chiller }}
$$

and

$$
\dot{E}_{i n}=\dot{Q}_{e f f, c o m b}-\dot{Q}_{e f f, c c}
$$

In analogy with the energy efficiency the exergetic efficiency for a GT-refrigeration unit is:

$$
\eta_{e x, c}=\frac{\dot{W}_{e f f, t}-\dot{W}_{\text {eff,comp }}-\dot{W}_{\text {eff,chiller }}}{\dot{Q}_{\text {eff,comb }}-\dot{Q}_{\text {eff,cc }}}
$$

For the present analysis let us define dimensionless terms as the exergetic power gain ratio $\left(P G R_{e x}\right)$ and exergetic thermal efficiency change $\left(T E C_{e x}\right)$ :

$$
P G R_{e x}=\frac{\left(\dot{E}_{\text {out }}\right)_{\text {withcooling }}-\left(\dot{E}_{\text {out }}\right)_{\text {withoutcooling }}}{\left(\dot{E}_{\text {out }}\right)_{\text {without cooling }}} \times 100 \%
$$

and

$$
T E C_{e x}=\frac{\eta_{e x, c}-\eta_{e x, n c}}{\eta_{e x, n c}} \times 100 \%
$$

Equations (51), (52), (57) and (58) can be easily employed to appraise the changes in the system performance, but they are not sufficient for a complete evaluation of the cooling method, the economics assessement of installing a cooling system follows.

\subsection{System Profitability}

To investigate the economic feasibility of retrofitting a gas turbine plant with an intake cooling system, the total cost of the cooling system is determined (Equation (33) or Equation (34)). The increase in the annual income cash flow from selling the additional electricity generation is also calculated. The annual exported energy by the coupled power plant system is;

$$
E(\mathrm{kWh})=\int_{0}^{t_{o p}} \dot{W}_{n e t} \mathrm{~d} t
$$

If the gas turbine's annual electricity generation without the cooling system is $E_{\text {without cooling }}$ and the cooling system increases the power generation to $E_{\text {with cooling, }}$, then the net increase in revenue due to the addition of the cooling system is:

$$
\text { Net revenue }=\left(E_{\text {with cooling }}-E_{\text {without cooling }}\right) C_{\text {els }}
$$

The profitability due to the coupled power plant sys- tem is defined as the increase in revenues due to the increase in electricity generation after deducting the expenses for installing and operating the cooling system as:

$$
\text { Profitability }=\left(E_{\text {with cooling }}-E_{\text {without cooling }}\right) C_{\text {els }}-C_{\text {total }}
$$

The first term in Equation (61) gives the increase in revenue and the second term gives the annual expenses of the cooling system. The profitability could be either positive, which means an economical incentive for adding the cooling system, or negative, meaning that there is no economical advantage, despite the increase in the electricity generation of the plant.

For more accurate evaluation the irreversibility of the different components are taken into consideration and an effective revenue (Revenue) $)_{\text {eff }}$ is defined by;

$$
\operatorname{Revenue}_{\text {eff }}=\int_{0}^{t_{\text {op }}}\left(\left(\dot{E}_{\text {out }}\right)_{\text {withcooling }}-\left(\dot{E}_{\text {out }}\right)_{\text {without cooling }}\right) C_{\text {els }} \mathrm{d} t
$$

\section{Results and Discussion}

The performance of the GT with water chiller cooler and its economical feasibility are investigated. The selected site is the Industrial City of Yanbu (Latitude $24^{\circ} 05^{\prime \prime} \mathrm{N}$ and longitude $38^{\circ} \mathrm{E}$ ) where a HITACH FS-7001B model GT plant is already connected to the main electric grid. Table 2 lists the main specs of the selected GT plant. The water chiller capacity is selected on basis of the maximum annual ambient temperature at the site. On $18^{\text {th }}$, 2010 , the dry bulb temperature $(D B T)$ reached $50^{\circ} \mathrm{C}$ at 14:00 O'clock and the relative humidity was $84 \%$ at dawn time. The recorded hourly variations in the DBT $\left(T_{\mathrm{o}}\right)$ and $R H_{o}$ are shown in Figure $\mathbf{4}$ and the values are listed in Table 2. Equation (48) gives the evaporator capacity of the water chiller (Ton Refrigeration) as function of the DBT and $R H$. Figure 5 shows that if the chiller is selected based on the maximum $D B T=50^{\circ} \mathrm{C}$ and $R H=$ $18 \%$, (the data at 14: O'clock), its capacity would be 2200 Ton. Another option is to select the chiller capacity based on the maximum $R H_{o}\left(R H_{\mathrm{o}}=0.83\right.$ and $T_{\mathrm{o}}=28.5^{\circ} \mathrm{C}$, 5:00 data), which gives 3500 Ton. It is more accurate, however, to determine the chiller capacity for the available climatic data of the selected day and determine the maximum required capacity, as seen in Figure 6; for the weather conditions at Yanbu City, a chiller capacity of 4200 Ton is selected it is the largest chiller capacity $\left(\dot{Q}_{e, r}\right)$ to handle the worst scenario as shown in Figure 6.

Equations (46) and (47) are employed to give the air properties leaving the cooling coil, assuming 0.5 contact factor and a chilled water supply temperature of $5^{\circ} \mathrm{C}$. All thermo-physical properties are determined to the accu- 
Table 2. Range of parameters for the present analysis.

\begin{tabular}{|c|c|}
\hline Parameter & Range \\
\hline \multicolumn{2}{|l|}{ Ambient air, Figure 4} \\
\hline Ambient air temperature, $T_{o}$ & $28^{\circ} \mathrm{C}-50^{\circ} \mathrm{C}$ \\
\hline Ambient air relative humidity, $R H_{o}$ & $18 \% \rightarrow 84 \%$ \\
\hline \multicolumn{2}{|c|}{ Gas Turbine, Model HITACH-FS-7001B } \\
\hline Pressure ratio, $P_{2} / P_{1}$ & 10 \\
\hline Net power, ISO & $52.4 \mathrm{MW}$ \\
\hline Site power & $37 \mathrm{MW}$ \\
\hline Turbine inlet temperature $T_{3}$ & $1273.15 \mathrm{~K}$ \\
\hline Volumetric air flow rate & $250 \mathrm{~m}^{3} \mathrm{~s}^{-1}$ at NPT \\
\hline Fuel net calorific value, $N C V$ & $46000 \mathrm{~kJ} \cdot \mathrm{kg}^{-1}$ \\
\hline Turbine efficiency, $\eta_{t}$ & 0.88 \\
\hline Air Compressor efficiency $\eta_{c}$ & 0.82 \\
\hline Combustion efficiency $\eta_{\text {comb }}$ & 0.85 \\
\hline \multicolumn{2}{|l|}{ Generator } \\
\hline Electrical efficiency & $95 \%$ \\
\hline Mechanical efficiency & $90 \%$ \\
\hline \multicolumn{2}{|l|}{ Water Chiller } \\
\hline Refrigerant & R22 \\
\hline Evaporating temperature, $T_{e}$ & $T_{\text {chws }}-T D_{e}{ }^{\circ} \mathrm{C}$ \\
\hline Superheat & $10 \mathrm{~K}$ \\
\hline Condensing temperature, $T_{c}$ & $\mathrm{~T}_{\mathrm{o}}+\mathrm{TD}_{\mathrm{c}} \mathrm{K}$ \\
\hline Condenser design temperature difference $T D_{c}$ & $10 \mathrm{~K}$ \\
\hline Evaporator design temperature difference TDe & $6 \mathrm{~K}$ \\
\hline Subcooling & $3 \mathrm{~K}$ \\
\hline Chilled water supply temperature, $T_{\text {chws }}$ & $5^{\circ} \mathrm{C}$ \\
\hline Chiller evaporator effectiveness, $\quad \varepsilon_{\text {eff }, e r}$ & $85 \%$ \\
\hline Chiller compressor energy use efficiency, $\eta_{e u}$ & $\begin{array}{c}85 \% \\
172 \$ / k W\end{array}$ \\
\hline \multicolumn{2}{|l|}{ Cooling Coil } \\
\hline Cooling coil effectiveness $\varepsilon_{e f f, c c}$ & $85 \%$ \\
\hline Contact Factor, CF & $50 \%$ \\
\hline \multicolumn{2}{|l|}{ Economics analysis } \\
\hline Interest rate $i$ & $10 \%$ \\
\hline Period of repayment (Payback period), $n$ & 3 years \\
\hline The maintenance cost, $\alpha_{m}$ & $10 \%$ of $C_{c h}^{c}$ \\
\hline Electricity rate, $C_{e l}$ (Equations (33) and (34)) & $0.07 \$ / \mathrm{kWh}$ \\
\hline Cost of selling excess electricity, $C_{e l s}$ (Equations (40) and (41)) & $0.07-0.15 \$ / \mathrm{kWh}$ \\
\hline Hours of operation per year, $t_{o p}$ & $7240 \mathrm{~h} / \mathrm{y}$ \\
\hline
\end{tabular}




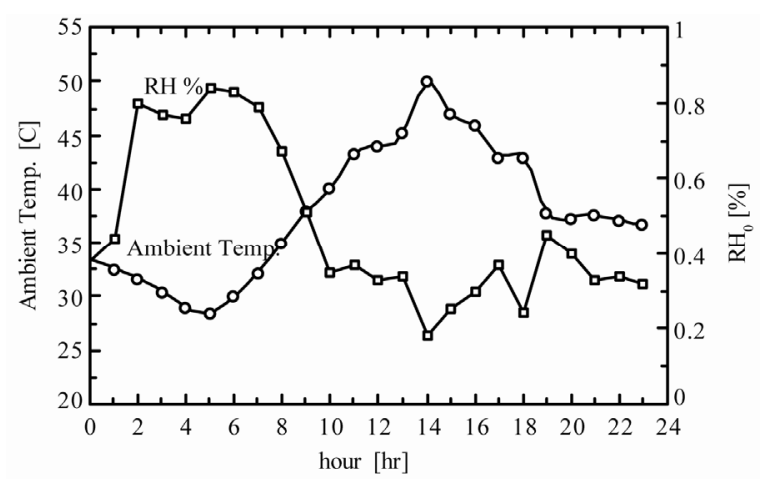

Figure 4. Ambient temperature variation and $R H$ for $18^{\text {th }}$ of August 2010 of Yanbu Industrial City.

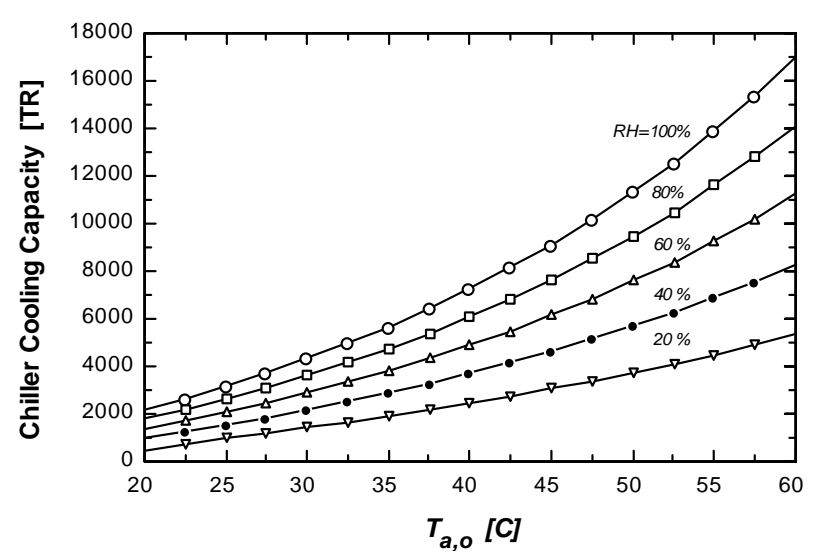

Figure 5. Dependence of chiller cooling capacity on the climatic conditions.

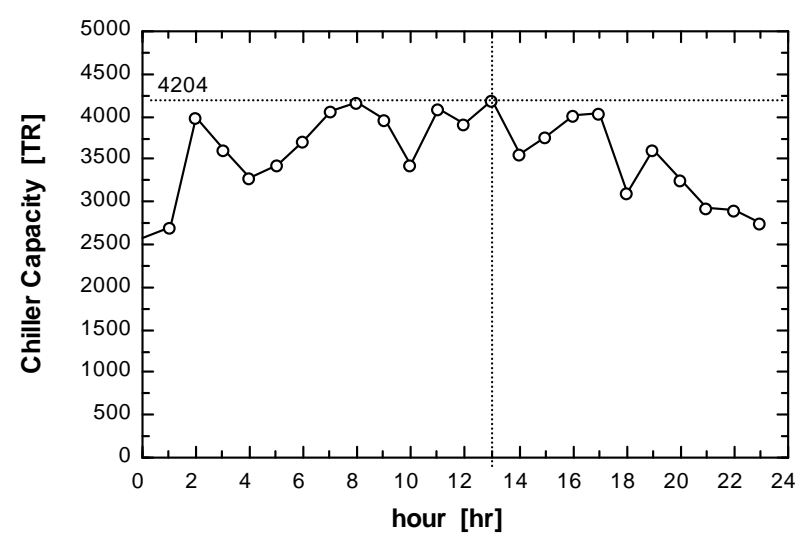

Figure 6. Chiller capacity variation with the climatic conditions of the selected design day.

racy of the Engineering Equation Solver (EES) software [36]. The result show that the cooling system decrease the intake air temperature from $T_{o}$ to $T_{l}$ and increases the relative humidity to $R H_{1}$ (Table 3 ).

Solution of Equations 51 and 52, using the data in Table 3, gives the daily variation in $P G R$ and $T E C$, Figure 7. There is certainly a potential benefit of adding the
Table 3. The ambient conditions and the cooling coil outlet temperature and humidity during $18^{\text {th }}$ August 2010 operation.

\begin{tabular}{|c|c|c|c|c|}
\hline Hour & $T_{o}^{\circ} \mathrm{C}$ & $R H_{o}$ & $T_{l}{ }^{\circ} \mathrm{C}$ & $R H_{l}$ \\
\hline 0 & 33.4 & 0.38 & 19.2 & 0.64 \\
\hline 1 & 32.6 & 0.44 & 18.8 & 0.70 \\
\hline 2 & 31.7 & 0.8 & 18.35 & 0.99 \\
\hline 3 & 30.5 & 0.77 & 17.75 & 0.98 \\
\hline 4 & 29.0 & 0.76 & 17.0 & 0.99 \\
\hline 5 & 28.5 & 0.84 & 16.75 & 0.97 \\
\hline 6 & 30.0 & 0.83 & 17.5 & 0.99 \\
\hline 7 & 32.2 & 0.79 & 18.6 & 0.96 \\
\hline 8 & 35.1 & 0.67 & 20.05 & 0.99 \\
\hline 9 & 38.0 & 0.51 & 21.5 & 0.84 \\
\hline 10 & 40.2 & 0.35 & 22.6 & 0.64 \\
\hline 11 & 43.3 & 0.37 & 24.15 & 0.69 \\
\hline 12 & 44.0 & 0.33 & 24.5 & 0.64 \\
\hline 13 & 45.2 & 0.34 & 25.1 & 0.66 \\
\hline 14 & 50.0 & 0.18 & 27.5 & 0.43 \\
\hline 15 & 47.0 & 0.25 & 26.0 & 0.53 \\
\hline 16 & 45.9 & 0.30 & 25.45 & 0.61 \\
\hline 17 & 43.0 & 0.37 & 24.0 & 0.69 \\
\hline 18 & 43.0 & 0.24 & 24.0 & 0.50 \\
\hline 19 & 37.9 & 0.45 & 21.45 & 0.76 \\
\hline 20 & 37.4 & 0.40 & 21.2 & 0.69 \\
\hline 21 & 37.6 & 0.33 & 21.3 & 0.60 \\
\hline 22 & 37.1 & 0.34 & 21.05 & 0.61 \\
\hline 23 & 36.8 & 0.32 & 20.90 & 0.58 \\
\hline
\end{tabular}

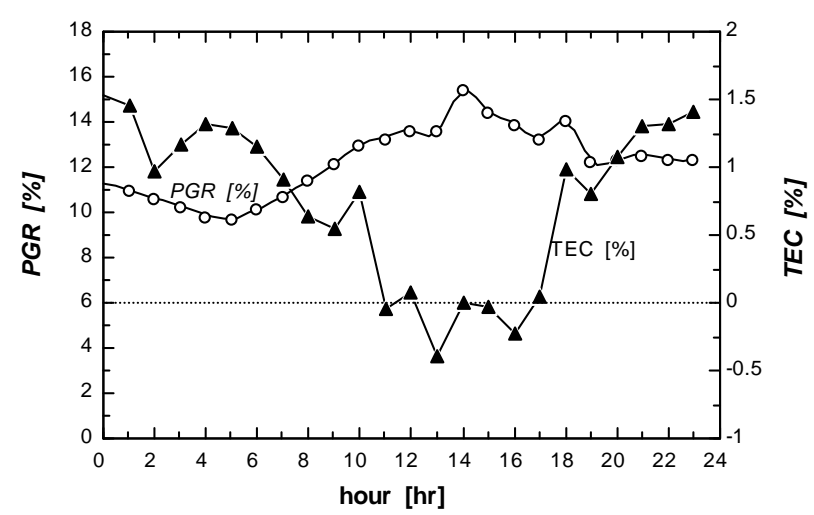

Figure 7. Variation of gas turbine $P G R$ and TEC during $18^{\text {th }}$ August operation. 
cooling system where there is an increase in the power output all the time, the calculated average for the design day is $12.25 \%$. The $P G R$ follows the same pattern of the ambient temperature; the increase in power of the GT plant reaches a maximum of $15.46 \%$, with a little change in the plant thermal efficiency. The practical illustrative application indicates that a maximum decrease in the thermal efficiency change of only $0.391 \%$ occurs at 13:00 PM when the air temperature is $45.2^{\circ} \mathrm{C}$, and $34 \%$ RH.

On basis of the second law analysis the exergetic power gain ratio $P G R_{e x}$ is still positive meaning that there is increase in output power but at a reduced value than that of the energy analysis.

Figure 8 shows that the power increase for the worst day of the year that varies between $7 \%$ to $10.4 \%$ (average $8.5 \%$ ) and the thermal efficiency drops by a maximum of $6 \%$. These results indicate the importance of the second law analysis.

Based on the daily variation of the ambient conditions on August $18^{\text {th }}$, assuming different values for selling the electricity $\left(C_{e l s}\right)$, Equation (60) gives the hourly revenues needed to payback the investment after a specified operation period (selected by 3 years). The different terms in Equations (50) and (60) are calculated and presented in Figure 9. The effect of the climate changes is quite obvious on both the total expenses (Figure 9) and the GT net power output (Figure 7). The variations in $C_{\text {total }}$ are due to the changes in $\dot{Q}_{e v}$ in Equation (50) that depends on $\left(T_{o}, T_{1}, \omega_{o}\right.$ and $\left.\omega_{1}\right)$. The revenue from selling additional electricity is also presented in the same figure, which shows clearly the potential of adding the cooling system. Figure 9 indicates that selling the electricity to the consumers at the same base price $\left(C_{e l s}=C_{e l}=0.07\right.$ $\$ / \mathrm{kWh}$ ) makes the cooling system barley profitable. The profit increases directly with the cost of selling the electricity. This result is interesting and encourages the utilities to consider a time-of-use tariff during the high demand periods. The profitability of the system, being the difference between the revenues and the total cost, is appreciable when the selling rate of the excess electricity generation is higher than the base rate of $0.07 \$ / \mathrm{kWh}$.
Economy calculations for one year with 7240 operation hours and for different electricity selling rates are summarized in Table 4. The values show that there is always a net positive profit starting after the payback period for different energy selling prices. During the first 3 years of the cooling system life, there is a net profit when the electricity selling rate increases to $0.15 \$ / \mathrm{kWh}$, nearly double the base tariff.

Figure 10 shows the effect of irreversibilities on the economic feasibility of using an air cooling system for the selected case. The effective revenue Equation (62)

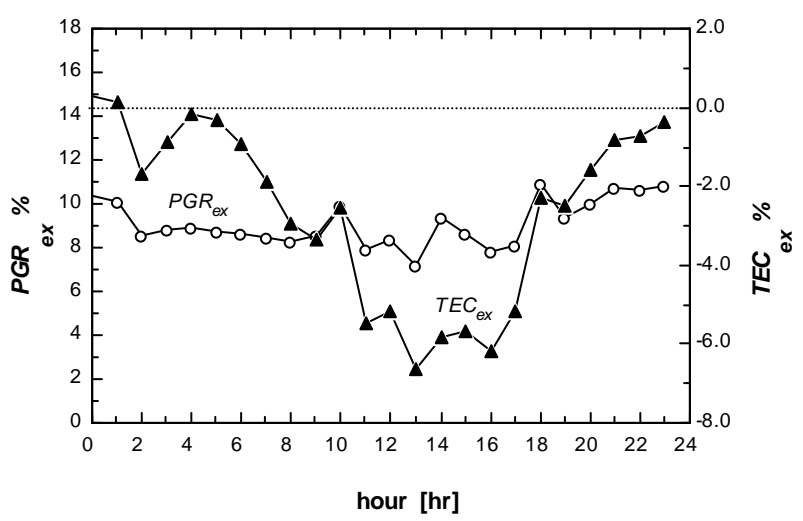

Figure 8. Variation of gas turbine exergetic $P G R_{e x}$ and $T E$ $C_{e x}$ during $18^{\text {th }}$ August operation.

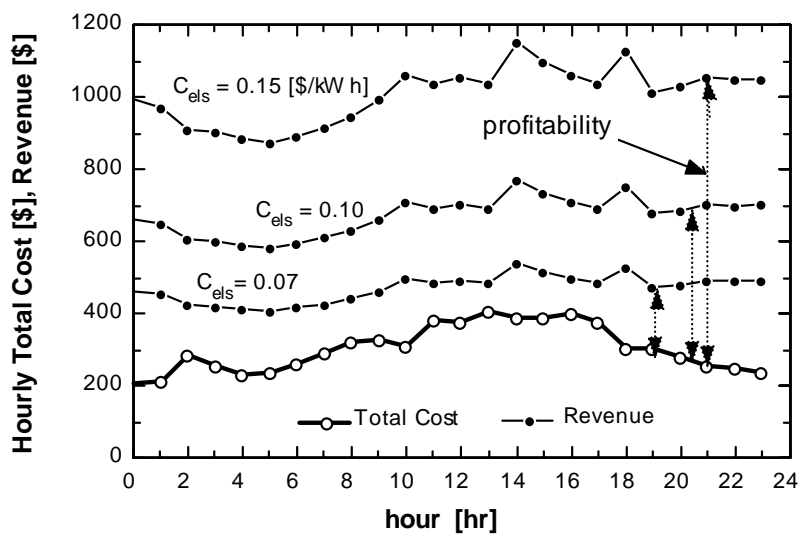

Figure 9. Variation of hourly total cost and excess revenue at different electricity selling rate.

Table 4. Annual net profits out of retrofitting a cooling system to a GT, HITACHI FS-7001B at Yanbu for different product tariff and 3 years payback period.

\begin{tabular}{|c|c|c|c|c|}
\hline $\begin{array}{l}\text { Electricity selling rate } \\
\qquad C_{e l s} \\
\end{array}$ & $\begin{array}{c}\text { Annuity-for Chiller, coil and } \\
\text { maintenance }\end{array}$ & $\begin{array}{l}\text { Annual operating } \\
\text { cost }\end{array}$ & $\begin{array}{l}\text { Annual net profit for the first } \\
3 \text { years }\end{array}$ & $\begin{array}{l}\text { Annual net profit for the } \\
\text { fourth year }\end{array}$ \\
\hline$\$ / \mathrm{kWh}$ & $\$ / y$ & $\$ / y$ & $\$ / y$ & $\$ / y$ \\
\hline 0.07 & $1,154,780$ & $1,835,038$ & $-1,013,600$ & +141180 \\
\hline 0.1 & $1,154,780$ & $1,835,038$ & $-166,821$ & $+987,962$ \\
\hline 0.15 & $1,154,780$ & $1,835,038$ & $1,244,978$ & $+2,399,758$ \\
\hline
\end{tabular}




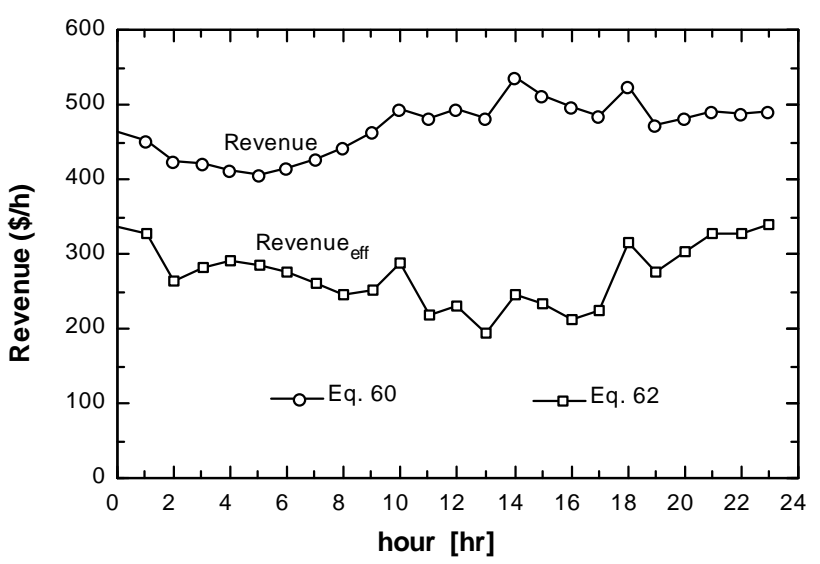

Figure 10. Effect of irreversibility on the revenue, $C_{\text {els }}=0.07$ $\$ / \mathbf{k W h}$.

(Revenue $_{\text {eff }}$ ) that can be accumulated from selling the net power output is reduced by $41.8 \%$ as a result of irreversibilities. The major contribution comes from the water chiller, where the irreversibility is the highest.

\section{Conclusions}

There are various methods to improve the performance of gas turbine power plants operating under hot ambient temperatures far from the ISO standards. One proven approach is to reduce the compressor intake temperature by installing an external cooling system. In this paper, a simulation model that consists of thermal analysis of a GT and coupled to a refrigeration cooler, exergy analysis and economics evaluation is developed. The performed analysis is based on coupling the thermodynamics parameters of the GT and cooler unit with the other variables as the interest rate, life time, increased revenue and profitability in a single cost function. The augmentation of the GT plant performance is characterized using the power gain ratio (PGR) and the thermal efficiency change term (TEC).

The developed model is applied to a GT power plant (HITACHI FS-7001B) in the city of Yanbu $\left(20^{\circ} 05^{\prime \prime} \mathrm{N}\right.$ latitude and $38^{\circ} \mathrm{E}$ longitude) $\mathrm{KSA}$, where the maximum DBT has reached $50^{\circ} \mathrm{C}$ on August $18^{\text {th }}, 2010$. The recorded climate conditions on that day are selected for sizing out the chiller and cooling coil capacities. The performance analysis of the GT shows that the intake air temperature decreases by 12 to $22 \mathrm{~K}$, while the PGR increases to a maximum of $15.46 \%$. The average increase in the plant power output power is $12.25 \%$, with insignificant change in plant thermal efficiency. The second law analysis show that the exergetic power gain ratio drops to an average of $8.5 \%$ with $6 \%$ maximum decrease in thermal efficiency.

In the present study, the profitability resulting from cooling the intake air is calculated for electricity rates between 0.07 and $0.15 \$ / \mathrm{kWh}$ and a payback period of 3 years. Cash flow analysis of the GT power plant in the city of Yanbu shows a potential for increasing the output power of the plant and increased revenues.

\section{REFERENCES}

[1] Cortes CPE, D. Williams, "Gas Turbine Inlet Cooling Techniques: An Overview of Current Technology," Proceedings Power GEN 2003, Las Vegas, 9-11 December 2003.

[2] T, Wang, X. Li and V. Pinniti, "Simulation of Mist Transport for Gas Turbine Inlet Air-Cooling," ASME International Mechanical Engineering Congress, Anaheim, 13-19 November 2009.

[3] M. Ameri, H. Nabati and A. Keshtgar, "Gas Turbine Power Augmentation Using Fog Inlet Cooling System," Proceedings ESDA04 $7^{\text {th }}$ Biennial Conference Engineering Systems Design And Analysis, Manchester, 2004.

[4] M. Ameri, H. R. Shahbazian and M. Nabizadeh, "Comparison of Evaporative Inlet Air Cooling Systems to Enhance the Gas Turbine Generated Power," International Journal of Energy Research, Vol. 31, 2007, pp. 483-503. doi:10.1002/er.1315

[5] M. Jonsson and J. Yan, "Humidified Gas Turbines-A Review of Proposed and Implemented Cycles," Energy, Vol. 30, 2005, pp. 1013-1078. doi:10.1016/j.energy.2004.08.005

[6] M. M. Alhazmy and Y. S. Najjar, "Augmentation of Gas Turbine Performance Using Air Coolers," Applied Thermal Engineering, Vol. 24, 2004, pp. 415-429. doi:10.1016/i.applthermaleng.2003.09.006

[7] M. M. Alhazmy, R. K. Jassim and G. M. Zaki, "Performance Enhancement of Gas Turbines by Inlet Air-Cooling in Hot and Humid Climates," International Journal of Energy Research, Vol. 30, 2006, pp. 777-797. doi:10.1002/er.1184

[8] S. Sanaye and M. Tahani, "Analysis of Gas Turbine Operating Parameters with Inlet Fogging and Wet Compression Processes," Applied Thermal Engineering, Vol. 30, 2010, pp. 234-244.

doi:10.1016/j.applthermaleng.2009.08.011

[9] T. C. Tillman, D. W. Blacklund and J. D. Penton, “Analyzing the Potential for Condensate Carry-Over from a Gas Cooling Turbine Inlet Cooling Coil," ASHRAE Transactions, Vol. 111, 2005, pp. 555-563.

[10] M. Chaker, C. B. Meher-Homji and M. Mee, "Inlet Fogging of Gas Turbine Engines-Part B: Fog Droplet Sizing Analysis, Nozzle Types, Measurement and Testing," ASME Proceedings of Turbo Expo 2002, Vol. 4, 2002. pp. 429-442.

[11] M. Chaker, C. B. Meher-Homji and M. Mee, "Inlet Fogging of Gas Turbine Engines-Part C: Fog Behavior in Inlet Ducts, Cfd Analysis and Wind Tunnel Experiments," ASME Proceedings of Turbo Expo 2002, Vol. 4, 2002, pp. 443-455.

[12] M. Chaker, C. B. Meher-Homji, Mee III and A. Nichol- 
son, "Inlet Fogging of Gas Turbine Engines Detailed Climatic Analysis of Gas Turbine Evaporation Cooling Potential in the USA," Journal of Engineering for Gas Turbines and Power, Vol. 125, No. 1, 2003, pp. 300-309. doi:10.1115/1.1519266

[13] B. C. Homji-Meher, T. Mee and R. Thomas, "Inlet Fogging of Gas Turbine Engines, Part B: Droplet Sizing Analysis Nozzle Types, Measurement and Testing," Proceedings of the ASME Turbo Expo 2002, Amsterdam, June 2002.

[14] H. Gajjar and M. Chaker, "Inlet Fogging for a $655 \mathrm{MW}$ Combined Cycle Power Plant-Design, Implementation and Operating Experience," ASME Proceedings of Turbo Expo 2003, Vol. 2, 2003, pp. 853-860.

[15] J. Elliot, "Chilled Air Takes Weather out of Equation," Diesel and Gas Turbine World Wide, October 2001, pp. 49-96.

[16] C. Yang, Z. Yang and R. Cai, "Analytical Method for Evaluation of Gas Turbine Inlet Air Cooling in Combined Cycle Power Plant, " Applied Energy, Vol. 86, 2009, pp. 848-856. doi:10.1016/i.apenergy.2008.08.019

[17] I. S. Ondrays, D. A. Wilson, N. Kawamoto and G. L. Haub, "Options in Gas Turbine Power Augmentation Using Inlet Air Chilling," Engineering Gas Turbine and Power, Vol. 113, 1991, pp. 203-211. doi:10.1115/1.2906546

[18] D. Punwani, T. Pierson, C. Sanchez and W. Ryan, "Combustion Turbine Inlet Air Cooling Using Absorption Chillers Some Technical and Economical Analysis and Case Summaries," ASHRAE Annual Meeting, Seattle, Washington, June 1999, p. 99.

[19] E. Kakarus, A. Doukelis and S. Karellas, "Compressor Intake Air Cooling in Gas Turbine Plants," Energy, Vol. 29, 2004, pp. 2347-2358. doi:10.1016/j.energy.2004.03.043

[20] W. Stewart and A. Patrick, "Air Temperature Depression and Potential Icing at the Inlet of Stationary Combustion Turbines," ASHRAE Transactions, Vol. 106, 2000, pp. 318 -327 .

[21] M. Farzaneh-Gord and M. Deymi-Dashtebayaz, "A New Approach for Enhancing Performance of a Gas Turbine (Case Study: Khangiran Refinery)," Applied Energy, Vol. 86,2009 , pp. 2750-2759. doi:10.1016/j.apenergy.2009.04.017

[22] G. M. Zaki, R. K. Jassim and M. M. Alhazmy, "Brayton Refrigeration Cycle for Gas Turbine Inlet Air Cooling," International Journal of Energy Research, Vol. 31, 2007, pp. 1292-1306. doi:10.1002/er.1302

[23] R. K. Jassim, G. M. Zaki and M. M. Alhazmy, "Energy and Exergy Analysis of Reverse Brayton Refrigerator for Gas Turbine Power Boosting," International Journal of
Exergy, Vol. 6, No. 2, 2009, pp. 143-165. doi:10.1504/IJEX.2009.023995

[24] J. R. Khan, W. E. Lear, S. A. Sherif and J. F. Crittenden, "Performance of a Novel Combined Cooling and Power Gas Turbine with Water Harvesting," ASME Journal of Engineering for Gas Turbines and Power, Vol. 130, No. 4, 2008. doi:10.1115/1.2830854

[25] D. C. Erickson, "Aqua Absorption Turbine Inlet Cooling," Proceedings of IMEC 03, ASME International Mechanical Engineering Congress \& Exposition, Washington D.C., 16-21 November 2003.

[26] D. C. Erickson, "Power Fogger Cycle," ASHRAE Transactions, Vol. 111, 2005, pp. 551-554.

[27] R. Gareta, L. M. Romeo and A. Gil, "Methodology for the Economic Evaluation of Gas Turbine Air Cooling Systems in Combined Cycle Applications," Energy, Vol. 29, 2004, pp. 1805-1818 doi:10.1016/j.energy.2004.03.040

[28] S. M. Hasnain, S. H. Alawaji, A. M. Al-Ibrahim and M. S. Smiai, "Prospects of Cool Thermal Storage Utilization in Saudi Arabia," Energy Conversion \& Management, Vol. 41, 2000, pp. 1829-1839. doi:10.1016/S0196-8904(00)00026-1

[29] R. J. Dossat, "Principles of Refrigeration," John Wiley and Sons, New York, 1997.

[30] A. J. Cleland, D. J. Cleland and S. D. White, "Cost-Effective Refrigeration, Short Course Notes," Institute of Technology and Engineering, Massey University, New Zealand, 2000.

[31] T. J. Kotas, "The Exergy Method of Thermal Plant Analysis,” Krieger, Malabar, 1995.

[32] R. K. Jassim, T. Khir, B.A. Habeebullah and G. M. Zaki, "Exergoeconomic Optimization of the Geometry of Continuous Fins on an Array of Tubes of a Refrigeration Air Cooled Condenser," International Journal of Energy, Vol. 2, No. 2, 2005, pp. 146-171. doi:10.1504/IJEX.2005.006985

[33] T. Khir, R. K. Jassim and G. M. Zaki, "Application of Exergoeconomic Techniques to the Optimization of a Refrigeration Evaporator Coil with Continuous Fins," Journal of Energy Resources Technology, Vol. 129, No. 3, 2007, pp. 266-277. doi:10.1115/1.2751507

[34] H. Zubair, "Personal Communication," Johnson Control International, Jeddah, Saudi Arabia.

[35] F. C. McQuiston, J. D. Parker and J. D. Spilter, "Heating, Ventilating and Air Conditioning: Design and Analysis," $6^{\text {th }}$ Edition, John Wily, New York, 2005.

[36] K. A. Klein and F. L. Alvarado, "EES-Engineering Equation Solver," Version 6.648 ND, F-Chart Software, Middleton, 2004. 


\section{Nomenclatures}

$A_{c c}$ Cooling coil heat transfer area, $\mathrm{m}^{2}$

$C_{c c}^{c}$ capital cost of cooling coil (\$)

$C_{c h}^{c}$ capital cost of chiller (\$)

$C_{e l}$ unit cost of electricity, $\$ / \mathrm{kWh}$

$c_{p} \quad$ specific heat of gases, $\mathrm{kJ} / \mathrm{kg} \mathrm{K}$

$C F$ contact factor

$E \quad$ energy $\mathrm{kWh}$

EES engineering Equation Solver

$h_{v} \quad$ specific enthalpy of water vapor in the air, $\mathrm{kJ} / \mathrm{kg}$

$i$ interest rate on capital

$\dot{I}$ exergy destruction, $\mathrm{kW}$

$k \quad$ specific heats ratio.

$\dot{m}$ mass flow rate, $\mathrm{kg} \mathrm{s}^{-1}$

$\dot{m}_{a} \quad$ air mass flow rate, $\mathrm{kg} / \mathrm{s}$

$\dot{m}_{c w}$ chilled water mass flow rate, $\mathrm{kg} / \mathrm{s}$

$\dot{m}_{r} \quad$ refrigerant mass flow rate, $\mathrm{kg} / \mathrm{s}$

$\dot{m}_{w}$ condensate water rate, $\mathrm{kg} / \mathrm{s}$

$N C V$ net calorific value, $\mathrm{kJ} \mathrm{kg}^{-1}$

$P$ pressure, $\mathrm{kPa}$

$P G R$ power gain ratio

$P_{o} \quad$ atmospheric pressure, $\mathrm{kPa}$

$P R$ pressure ratio $=\mathrm{P}_{2} / \mathrm{P}_{1}$

$\dot{Q}_{h}$ heat rate, $\mathrm{kW}$

$\dot{Q}_{e, r}$ chiller evaporator cooling capacity, $\mathrm{kW}$

$\dot{Q}_{c c}$ cooling coil thermal capacity, $\mathrm{kW}$
$\dot{S}$ entropy, $\mathrm{kJ} / \mathrm{K}$

$t$ time, $\mathrm{s}$

$T \quad$ Temperature, $\mathrm{K}$

$T E C$ thermal efficiency change factor

$U$ overall heat transfer coefficient, $\mathrm{kW} / \mathrm{m}^{2} \mathrm{~K}$

$x$ quality.

$\dot{W}$ power, $\mathrm{Kw}$

\section{Greek Symbols}

$\eta \quad$ efficiency

$\varepsilon_{\text {eff }}$ effectiveness, according to subscripts

$\omega$ specific humidity (also, humidity ratio), according to subscripts, $\mathrm{kg} / \mathrm{kg}_{\text {dry air }}$

\section{Subscripts}

a dry air

$c \quad$ with cooling

cc cooling coil

ch chiller

comb combustion

comp compressor

eff effective

el electricity

$f$ fuel

$g$ gas

$n c$ no cooling

$o$ ambient

$t$ turbine

$v$ vapor 